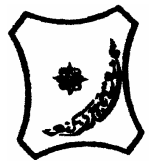

Bayero Journal of Pure and Applied Sciences, 4(2): 186 - 191

Received: October, 2011

Accepted: December, 2011

ISSN $2006-6996$

\title{
ENERGY- DRINKS: COMPOSITION AND HEALTH BENEFITS
}

\author{
*Yunusa, I. $^{1}$ and Ahmad, I. M. ${ }^{2}$ \\ ${ }^{1}$ Department of Food Science and Technology, Kano University of Science and Technology, Wudil. PMB 3244, \\ Kano. \\ ${ }^{2}$ Department of Science and Laboratory Technology, School of Technology, Kano State Polytechnic. \\ *Correspondence author: isayunusa@yahoo.com
}

\begin{abstract}
In recent years, there has been an increase in the consumption of energy drinks, containing besides calories, other ingredients suspected to boost mental, emotional and physical alertness of the consumers. Such drinks are widely consumed by young people for a variety of reasons. However, from a public health point of view, little seems to be understood of the health benefits and other implications of these drinks by their consumers. Therefore, the understanding that energy drinks have stimulating properties that can boost heart beat rate and blood pressure, dehydrate the body, aggravate the effects of other stimulants, and prevent sleep may help as a decision making tools for the consumers of such products. This review examines some of the important active ingredients of energy drinks, their origins, sources, benefits and side effects. It is concluded that energy drinks, despite the variations in brand name contain bio-active ingredients; therefore further research is needed on their potential hazards.
\end{abstract}

Keywords: Energy drinks, Composition, Effects, Consumers

\section{INTRODUCTION}

Energy drinks refer to beverages that contain, besides calories, caffeine in combination with other presumed energy-enhancing ingredients such as taurine, herbal extracts, and B vitamins (Heckman et al., 2010). They first appeared in Europe and Asia in the 1960s in response to consumer demand for a dietary supplement that would result in increased energy (Reissig et al., 2009). In 1962, a Japanese company, Taisho Pharmaceuticals, launched Lipovitan D, one of the very first energy drinks, which is still dominating the Japanese market (Taisho Pharmaceutical Co. Ltd., 2009).

Energy drinks fall into the category of functional beverages, which also encompasses sports and nutraceutical drinks (Datamonitor, 2008). Sports drinks are designed to be consumed before or during exercise to prevent dehydration, supply carbohydrates, provide electrolytes and typically do not contain caffeine (Coombes and Hamilton, 2000). Nutraceutical beverages, on the other hand, are designed to promote and enhance health, usually containing bioactive compounds such as concentrated extracts from teas, fruits, and vegetables or herbs (Heckman et al., 2010). Additionally, some nutraceutical beverages are found to be fortified with vitamins and minerals and contain significant levels of antioxidants, particularly polyphenols. In some instances, energy drinks could overlay into the nutraceutical beverage category depending on their composition. The energy drink segment encompasses an array of options including ready-to-drink (RTD), shots, and in powder form (Heckman et al., 2010).

Currently, there are more than 300 varieties of energy drinks representing more than 200 brands in the United States alone, all purporting to increase energy, longevity, and vitality in some form or another (Energyfiend, 2009). It appears that energy drinks are the new drinks for the Nigerian male and female, there appears to be a new craze and craving for energy drinks (Nworah, 2007). Both young and old are consuming these energy drinks as if they are going out of fashion (Nworah, 2007). Athletes initially were the primary consumers of energy drinks, however, as the energy drink market grew and expanded into various niche markets, athletes are no longer the primary target. Today, majority of energy drinks are targeted at teenagers and young adults 18 to 34 year old due to this generation's on-the-go lifestyle and receptiveness to advertisements for these types of products (Lal, 2007). Another report found that about one-half of college students consume at least 1 energy drink per month in the hope to increase their energy level, to compensate for a lack of sleep or to mix with alcohol (Miller, 2008).

A review presented at the 2007 IFE (Intl. Franchise Expo) Americas Food and Beverage Show confirmed that energy drink companies' primary target market was adolescents and young adults (Agriculture and Agri-Food Canada, 2008). Research suggests that energy drink formulations, in addition to increasing energy utilization, may also improve mood, enhance physical endurance, reduce mental fatigue, and increase reaction time. However, in most cases, the corresponding mechanisms of action are not clear (Heckman et al., 2010). In addition, concerns have been raised over their safety and with a currently weak regulatory environment; efforts need to be made to ensure consumer safety. This article is aimed to review some ingredients contained in most energy drinks as well as identify the health benefits associated with the consumptions of such drinks. 


\section{Active Ingredients of Energy drinks Caffeine}

Caffeine has a similar chemical structure to that of adenosine allowing caffeine to attach to the adenosine receptors. The main mechanism of action of caffeine, in concentrations typically achieved after the consumption of a caffeinated beverage, is to act as an adenosine receptor blocker in the brain (Pettenuzzo et al., 2008). The blockage of adenosine to the neurons causes the sleep promoting effects of adenosine to stop, resulting in the neurons speeding up instead of slowing down (Ferre, 2008). Caffeine is also known to increase the secretion of epinephrine, which can lead to a variety of secondary metabolic changes that can positively affect physical or mental performance (Graham, 2001). Once ingested, caffeine is rapidly absorbed from the gastrointestinal tract and undergoes demethylations which result in paraxanthine $(84 \%)$, theobromine $(12 \%)$, and theophylline (4\%); with the xanthenes theobromine and theophylline having very similar chemical structures compared to caffeine (Safranow and Machoy, 2005).

Caffeine has been widely studied in a variety of areas regarding human health and performance and it is evident that caffeine consumption can increase energy utilization (Smit and Rogers, 2002). Many studies also confirm its ability to enhance mood and alertness (Lorist and Tops, 2003), exercise performance (Doherty and Smith, 2004), the speed at which information is processed, awareness, attention, and reaction time (Cysneiros et al., 2007). Caffeine has also been shown to reduce some of the negative side effects associated with sleep loss. Some studies suggest that caffeine can contribute to improved alertness and performance at doses of 75 to $150 \mathrm{mg}$ after acute sleep loss and doses of 200 to $600 \mathrm{mg}$ after a night or more without sleep (Bonnet et al., 2005). Caffeine also has a stimulatory effect on thermogenesis (Bracco et al., 1995).

In addition, caffeine consumption has also been linked to reducing food intake (Lima et al., 2005) and to promote lipolysis in both animals and humans (LopezGarcia et al., 2006). A review regarding caffeine consumption concluded that among the healthy adult population, a moderate daily caffeine intake of $\leq 400$ $\mathrm{mg}$ (equivalent to $6 \mathrm{mg} / \mathrm{kg} /$ day for a $65 \mathrm{~kg}$ person) was not associated with any adverse effects (Nawrot et al., 2003). Nonetheless, caution should be exercised in regard to the amount of caffeine consumed per day. Caffeine has a long history of safe use and overwhelming scientific evidence maintains that when consumed in moderation (300 to 400 $\mathrm{mg} /$ day/adult) no adverse effects should occur (Heckman et al., 2010).

\section{Taurine}

Taurine (2-aminoethyl sulfonic acid) is sulfur containing amino acid that is the most abundant amino acid found naturally in our bodies, primarily in the retina and skeletal and cardiac muscle tissues (Imagawa et al., 2009). Taurine is derived from the metabolism of methionine and cysteine (Stipanuk, 2004). It is also present in common food items such as meat and fish. It has been estimated that the average daily human intake of taurine is between 40 and $400 \mathrm{mg}$ (Shao and Hathcock, 2008). The incorporation of taurine into energy drinks and other products has increased a great deal over the past 10 years with taurine also being one of the most extensively used and studied amino acids (Shao and Hathcock, 2008).

Taurine is associated with a variety of physiological functions including neuro-modulation, cellular membrane stability, and modulation of intracellular calcium levels, both, in vitro and in vivo (Brosnan and Brosnan, 2006). However, further research is needed to better explain the underlying mechanisms of action (Heckman et al., 2010). Furthermore, taurine has been seen to enhance endurance performance and to aid in the reduction of lactic acid buildup after exercise (Imagawa et al., 2009). In the body, taurine undergoes mainly conjugation to form bile salts as well as degradation to sulfate (Munro and Renwick, 2006). This metabolism allows for larger dietary intakes of taurine, with excess eliminated unchanged in the urine (Munro and Renwick, 2006). Methods have been developed to discriminate between synthetic taurine and that derived from natural sources, suggesting an inferior nutritional value of the former (Gioacchini et al., 1995). However, more research is needed to conclude whether there is a significant physiological difference between taurine from natural or synthetic sources (Heckman et al., 2010). The synthetic taurine that is present in energy drinks is found in very large concentrations.

Taurine analysis of 80 different energy drinks showed an average concentration of $3180 \mathrm{mg} / \mathrm{L}$ which is equivalent to $753 \mathrm{mg} / 8$ ounce (Triebel et al., 2007). Several studies have been conducted aimed to determine the effect of taurine at various dosages ranging from 375 to $8000 \mathrm{mg} /$ day, resulting in no adverse effects (Ikeda, 1977). Other studies have also looked into the safety of taurine in humans and found no adverse effects (Zhang et al., 2004). Although there has been no evidence showing taurine to cause any adverse health effects, concern has been raised since not enough research has been conducted on the effects of large quantities of taurine in combination with other ingredients commonly found in energy drinks (Heckman et al., 2010).

\section{Guarana}

Guarana comes from the Paullinia cupana plant, indigenous to South America. It originated in the Amazon basin in Brazil, where it has had a long history of use (Angelo et al., 2008). It is commonly known for its small-berry like fruit it produces, which contains 1 to 3 dark seeds, which accounts for the only edible part of the guarana plant (Scholey and Haskell, 2008). The seeds contain a significant amount of caffeine, with $1 \mathrm{~g}$ of guarana being equivalent to about $40 \mathrm{mg}$ caffeine (Finnegan, 2003). 
Guarana contains other xanthine alkaloids, specifically theobromine and theophylline, however, at much lower levels compared to caffeine (Weckerle et al., 2003). In addition to the caffeine content, guarana also contains relatively high amounts of saponins, flavonoids, and tannins, all contributing to its bioactive properties including its antioxidant activity (Mattei et al., 1998).

Guarana has become an increasingly common natural additive in energy drinks in recent years largely for its stimulatory effect (Scholey and Haskell, 2008). It has been stated that the caffeine from guarana is released at a slower rate compared to pure caffeine, giving off a more subtle and lengthier stimulatory effect (Scholey and Haskell, 2008). It is purported that this slower release is due to guarana being insoluble in water as well as containing tannins and saponins (Edwards et al., 2005). There is, however, no conclusive research that shows the caffeine release and absorption from guarana to be any different from that of pure caffeine (Bempong and Houghton, 1992). Guarana has been suggested to improve cognitive performance, mental fatigue, and mood at physiologically relevant dosages; an effect supported by several research studies (Scholey and Haskell, 2008). Guarana has also been associated with inducing lipid metabolism, probably due to its methylxanthine content (Lima et al., 2005). Additionally, guarana has been shown to exert no toxic effects when consumed both in acute high dosages as well as in chronic lower dosages (Mattei et al., 1998).

\section{Ginseng}

Ginseng is a herb that has been used for over 2000 years by people in East Asian countries including China, Japan, and Korea as a remedy for various diseases and for promoting longevity (Nam et al., 2005). Panax ginseng is the primary commercial species and is often referred to as Korean or Asian ginseng. Siberian ginseng (Eleutherococcus senticosus) is not truly a ginseng since it contains eleutherosides as its active constituent and no ginsenosides. $P$. ginseng is a small, shade-loving perennial shrub that reaches about $60 \mathrm{~cm}$ in height and belongs to the plant family Araliacae. The entire ginseng plant has been used for medicinal purposes; however, the root is the most prominent and dominates the commercial sales. The roots are typically not harvested until after the 5th or 6th year of growth when their ginsenoside concentrations are at their peak (Mahady et al., 2001). After harvest, P. ginseng can undergo further processing, including drying and bleaching of the root with sulfur dioxide forming "white ginseng" or steaming the root and air-drying it to form "red ginseng" (Mahady et al., 2001).

\section{Yerba mate}

Yerba mate comes from the Ilex paraguariensis plant which is native to South America where its main function is for the production of yerba mate tea (Heck and de Mejia, 2007). Yerba mate tea is a commonly consumed beverage in South American countries and has been for centuries; however, it is increasing in popularity globally due to its content of a variety of bioactive components including polyphenols, xanthines, flavonoids, saponins, amino acids, minerals, and vitamins (Heck and de Mejia, 2007). The abundant array of phytochemicals present in yerba mate has been connected to various health benefits. Yerba mate possesses anti-inflammatory and antidiabetic properties as well as acts as an inhibitor to oxidative stress (Markowicz-Bastos et al., 2007). Moreover, yerba mate has shown in-vitro cytotoxicity to cancer cells and inhibition against Topoisomerase II, which plays a role in cell division and therefore works to inhibit cancer cell proliferation (Heck and de Mejia, 2007); however, in vivo studies are needed (Heckman et al., 2010). Yerba mate also has a positive impact on the management of obesity, both in vivo and in vitro (Arcari et al., 2009). The consumption of yerba mate significantly improved the serum lipid parameters in normolipidemic and dyslipidemic individuals (de Morais et al., 2009). Furthermore, yerba mate enhanced the reduction in LDLcholesterol levels in individuals who were also under statin therapy (de Morais et al., 2009).

In addition, yerba mate is a central nervous system stimulant due to its high caffeine concentration, which is the primary reason for yerba mate to be incorporated into energy drink formulations. The caffeine concentration in 1 cup (8 ounce) of yerba mate tea is equivalent to about $78 \mathrm{mg}$, which is very comparable to 8 ounce of Red Bull, which contains $80 \mathrm{mg}$ (Heck and de Mejia, 2007). On the other hand, concerns have been raised regarding an association between yerba mate and the occurrence of certain types of cancer, specifically oral, esophageal, lung, bladder, and renal (Heck and de Mejia, 2007).

However, there is no conclusive evidence that this association is a result of the consumption of yerba mate but rather due to various lifestyle choices including smoking and excessive alcohol consumption. In addition, these cases have primarily been reported in certain areas of South America where large amounts of yerba mate are consumed at very hot and damaging temperatures which could lead to increased absorption of carcinogens found in cigarette smoke or other environmental pollutants (Heck and de Mejia, 2007).

\section{B vitamins}

B vitamins are a group of 8 individual water-soluble vitamins, usually referred to as the $B$ complex when grouped together, and all play essential roles in cellular processes. $B$ vitamins are incorporated into many of the mainstream energy drinks. A typical can of $250 \mathrm{~mL}$ may contain $360 \%$ of the recommended daily allowance (RDA) of B6, $120 \%$ of B12, and $120 \%$ of B3 (niacin). The container size varies among brands and it may hold multiple servings.

The addition of excess amounts of $B$ vitamins is also observed in the more extreme energy drinks like 5-Hour Energy which contains $8333 \%$ of the RDA for vitamin B12 and $2000 \%$ of the RDA for B6.

It is claimed that the consumption of these large amounts of B vitamins increases mental alertness and focus, as well as improves mood. The average person, however, consumes the RDA of $B$ vitamins from a typical diet since B vitamins are found in a variety of foods including bananas, lentils, potatoes, tuna, and turkey. Vitamins B2 (riboflavin), B3 (niacin), B6 (pyridoxine, pyridoxal, pyridoxamine), and B12 are the most common of the $B$ vitamins that are incorporated into energy drink formulations. Vitamin B2 is a coenzyme in the metabolism of carbohydrates. Vitamin B3 plays a major role as a coenzyme in energy metabolism, fat synthesis, and fat breakdown (Wardlaw and Smith, 2009). 
Vitamin B6 is a group of 3 structurally similar compounds that all can be converted into the vitamin B6 coenzyme which aids in the utilization of carbohydrates, fats, and proteins (Wardlaw and Smith, 2009). Vitamin B12 assists in folate metabolism and in nerve function (Wardlaw and Smith, 2009). Since all of the B vitamins are water soluble, once the RDA has been met, the excess vitamins are excreted from the body via urine. Although the consumption of a large amount of B vitamins does not possess any adverse health effects, the logic behind the extreme amounts of $\mathrm{B}$ vitamins in these beverages is not well rationalized (Heckman et al., 2010).

\section{Ginkgo Biloba}

Ginkgo Biloba is an ingredient named after the rare tree it originates from. It is believed to help with memory retention, concentration, circulation, acts as an antidepressant, and even shows signs of helping people with Alzheimer's. The German government recognizes it as something that helps with memory loss, concentration, and depression. $60 \mathrm{mg}$ is a standard supplementation dose. However, most energy drinks do not contain enough ginkgo to be of any benefit. People on antidepressants shouldn't take ginkgo and some of the other side effects include blood thinning, nausea, vomiting, diarrhea, headaches, dizziness, heart palpitations, and restlessness (Energy Fiend, 2009).

\section{L-Carnitine}

L-Carnitine is an amino acid usually created by the liver and kidneys; it helps metabolism and energy levels. Because of the way it interacts with the body, it may act as a thermogenic and help increase weight loss and endurance during exercise. The need to supplement this amino acid is still not clear. D-Carnitine is "inactive" and may actually hurt endurance levels. Rare sides effects include include nausea, vomiting, abdominal pain, and diarrhea (Kavita et al., 2008).

\section{Glucuronolactone}

Glucuronolactone (DGL) occurs naturally in the human body as glucose is broken down by the liver. All connective tissue contains this compound. DGL is believed to aid in detoxification, freeing hormones and other chemicals, and the biosynthesis of vitamin C. It is placed in energy drinks because it is believed to help with

\section{REFERENCES}

Agriculture and Agri-Food Canada (2008): The energy drink segment in North America. Available from: $<$ http://Www.ats.agr.gc.ca/us/4387_e.htm\#2 $>$.

Alford, C., Cox, H. and Wescott, R. 2001): The effects of Red Bull energy drink on human performance and mood. Amino Acids. 21:139-50.

Angelo, P., Nunes-Silva, C., Brigido, M., Azevedo, J., Assuncao, E., Sousa, A., Patricio, F., Rego, M., Peixoto, J., Olivea, W., Freitas, D., Almeida, E., Viana, A., Souza, A., Andrade, E., Acosta, P., Batista, J., Walter, M., Leomil, L., Anjos, D., Coimbra, R., Barbosa, M., Honda, E., Pereira, S., Silva, A., Pereira, J., Silva, M., Marins, M., Holanda, F., Abreu, R., Pando, S., Goncalves, J., Carvalho, M., Leal-Mesquita, E., Silveira, M., Batista, W., Atroch, A., Franca, S., Porto, J., Schneider, M., and Astolfi-Filho, S. (2008): Guarana (Paullinia cupana var. sorbilis), an glycogen depletion by preventing other substances from depleting glycogen supplies in the muscles (Kavita et al., 2008).

\section{Creatine}

Creatine is naturally obtained by eating meat. Creatine helps with supplying energy to the muscles and is usually found in energy drinks and products that are marketed to body builders (Kavita et al., 2008).

\section{Acai Berry}

Acai Berry is an ingredient (pronounced ah-sah-ee) finding its way into more and more energy drinks. Acai berry comes from the Acai Palm tree which is found in South America. The berries are rich in anti-oxidants, but not as much as a concord grape or blueberry. Most of the acai berry benefits have no scientific basis and are attributed to marketing hype (Energy Fiend, 2009).

\section{Milk Thistle}

Milk Thistle is an ingredient mainly found in few energy drinks, used as a liver detoxifying agent. It is placed in energy drinks not really for any energy enhancing properties but as a counter agent to mixing energy drinks with alcohol as milk thistle is supposed to help with hangovers and detoxing the liver from alcohol. However, studies show that the amount put in energy drinks would hardly be any benefit to consumers (Kavita et al., 2008).

\section{L-theanine}

L-theanine seems to be the new ingredient showing up many new drinks. It is an amino acid that according to recent studies has shown to calm the brain to enhance concentration. This amino acid comes simply from tea leaves (Kavita et al., 2008).

\section{CONCLUSIONS AND RECOMMENDATIONS}

Energy drinks contain bio-active ingredients that may likely stimulate brain and other vital organs of their consumers. These stimulatory effects may be positive but sometimes could be detrimental to the health of their consumers. It is therefore, recommended that researches need to be carried out to ascertain the extent of consumption by the target youth and adolescents and to further authenticate the biochemical interactions of these products.

anciently consumed stimulant from the Amazon rain forest: the seeded-fruit transcriptome. Plant Cell Rep 27:117-24.

Arcari, D. P., Bartchewsky, W., Dos Santos, TW., Oliveira, K. A., Funck, A., Pedrazzoli, J., De Souza, M. F., Saad, M. J., Bastos, D. H., Gambero, A., Carvalho, P. D. and Riberiro, M. L. (2009). Antiobesity effects of yerba mate extract (Ilex paraguariensis) in high-fat diet-induced obese mice. Obesity. 17:2127-33.

Bempong, D. K. and Houghton, P. J. (1992): Dissolution and absorption of caffeine from guarana. $J$ Pharm Pharmacol. 44:769-71.

Bonnet, M. H., Balkin, T. J., Dinges, D. F., Roehrs, T., Rogers, N. L. and Wesensten, N. J. (2005): The use of stimulants to modify performance during sleep loss: a review by the Sleep Deprivation and Stimulant Task Force of the American Academy of Sleep Medicine. Sleep. 28:1163-87. 
Bracco, D., Ferrarra, J. M., Arnaud, M. J., Jequier, E. and Schutz, Y. (1995): Effects of caffeine on energy metabolism, heart rate, and methylxanthine metabolism in lean and obese women. $A m \mathrm{~J}$ Physiol Endocrinol Metab. 269:E671-78.

Brosnan, J. T. and Brosnan, M. E. (2006): The sulfurcontaining amino acids: an overview. $J$ Nutr 136(6 Supp/):1636S-40S.

Bruce, C. R., Anderson, M. E., Fraser, S. F., Stepto, N. K., Klein, R., Hopkins, W. G. and Hawley, J. A. (2000): Enhancement of 200-m rowing performance after caffeine ingestion. Med $\mathrm{SC}$ Sports Exerc. 32:1958-63.

Carvajal-Sancho, A. and Moncada-Jimenez, J. (2005): The acute effect of an energy drink on the physical and cognitive performance of male athletes. Kinesiol Slovenica. 11:5-16.

Coombes, J. S. and Hamilton, K. L. (2000): The effectiveness of commercially available sports drinks. Sports Med. 29:181-209.

Cysneiros, R. M., Farkas, D., Harmatz, J. S., Von Moltke, L. L. and Greenblatt, D. J. (2007): Pharmacokinetic and pharmacodynamic interactions between zolpidem and caffeine. Clin Pharmacol Ther. 82:54-62.

Datamonitor (2008): Functional drinks in the United States. Available from http://www.datamonitor.com .

De Morais, E. C., Stefanuto, A., Klein, G. A., Bonaventura, B. C. B., De Andrade, F., Wazlawik, E., Di Pietro, P. F., Maraschin, M. and De Silva, E. L. (2009): Consumption of yerba mate (Ilex paraguariensis) improves serum lipid parameters in healthy dyslipidemic subjects and provides additional LDL-cholesterol reduction in individuals on statin therapy. J Agric Food Chem. 57:8316-24.

Dentzer, D. L., Ragsdale, F. R. and Wilson, T. (2009): Effects of monster energy drink on cardiovascular and renal function. FASEB J. 23:901.1.

Doherty, M. and Smith, P. M. (2004): Effects of caffeine ingestion on exercise testing: a meta-analysis. Int J Sport Nutr Exerc Metab. 14:626-46.

Dunwiddie, T. V. and Mansino, S. A. (2001): The role and regulation of adenosine in the central nervous system. Ann Rev Neurosci. 24:31-55.

Edwards, H. G. M., Farwell, D. W., De Oliveira, L. F. C., Aliac, J. M., Le Hyaric, M. and De Ameida, M. V. (2005): FT-Ramen spectroscopic studies of guarana and some extracts. Anal Chim Acta. 532:177-86.

Energy-Fiend

(2009):

http://www.energyfiend.com/category/energydrinks >.

Ferre, S. 2008): An update in the mechanisms of the psychostimulant effects of caffeine. $J$ Neurochem. 105:1067-79.

Ferreira, S. E., De Mello, M. T., Rossi, M. V. and Souzaformigoni, M. L. (2004): Does an energy drink modify the effects of alcohol on a maximal effort test? Alcohol Clin Exp Res. 28:1408-12.
Finnegan, D. (2003): The health effects of stimulant drinks. Br Nutr Found Nut Bull. 28:147-55.

Geiss, K. R., Jester, I., Falke, W., Hamm, M. and Waag, K. L. (1994): The effect of a taurine-containing drink on performance in 10 endurance-athletes. Amino Acids. 7:45-56.

Gioacchini, A. M., Roda, A., Cipolla, A., Parenti, M. and Baraldini, M. (1995): Differentiation between natural and synthetic taurine using the ${ }^{13} \mathrm{C} /{ }^{12} \mathrm{C}$ isotope ratio. Rapid Comm Mass Spectrom. 9:1106-8.

Graham, T. E. (2001): Caffeine and exercise: metabolism, endurance and performance. Sports Med. 31:785-807.

Heck, C. I. and De Mejia, E. G. (2007): Yerba mate tea (Ilex paraguariensis): a comprehensive review on chemistry, health implications, and technological considerations. $J$ Food Sci. 72:138-51.

Heckman, M. A., Sherry, K. and De Mejia, E. G. (2010): Energy Drinks: An Assessment of Their Market Size, Consumer Demographics, Ingredient Profile, Functionality, and Regulations in the United States. Comprehensive Reviews in Food Science and Food Safety. 9 (3): 303-317.

Imagawa, T. F., Hirano, I., Utsuki, K., Horie, M., Naka, A., Matsumoto, K. and Imagawa, S. (2009): Caffeine and taurine enhance endurance performance. Int J Sports Med. 30:485-8.

Ikeda, H. (1977): Effects of taurine on alcohol withdrawal. Lancet. 2:509.

Ivy, J. L., Kammer, L., Ding, Z., Wang, B., Bernard, J. R., Liao, Y. H. and Hwang, J. (2009): Improved cycling time-trial performance after ingestion of a caffeine energy drink. Int J Sport Nutr Exerc Metab. 19:61-78.

Kavita, M., Babu, M. D., Richard, J., Church, M. D. and Lewander, M. D. (2008): "Energy Drinks: The New Eye-Opener For Adolescents". Clinical Pediatric Emergency Medicine. < http://www.energyfiend.com/category/energydrinks

Kovacs, E. M. R., Stegen, J. H. C. H. and Brouns, F. (1998): Effect of caffeinated drinks on substrate metabolism, caffeine excretion, and performance. J Appl Physiol. 85:709-15.

Lal, G. G. 2007): Getting specific with functional beverages. Food Technol. 61(12):25-31.

Lima, W. P., Carnevali, L. C., Eder, R., Fernando, L., Costa Rosa, B. P., Bacchi, E. M. and Seelaender, M. C. L. (2005): Lipid metabolism in trained rats: effect of guarana (Paullinia cupana Mart.) supplementation. Clin Nutr. 24:1019-28.

Lopez-Garcia E, Van Dam RM, Rajpathak S, Willett WC, Manson JE, Hu FB. (2006): Changes in caffeine intake and long-term weight change in men and women. Am J Clin Nutr. 83:674-80.

Lorist, M. and Tops, M. M. (2003): Caffeine, fatigue and cognition. Brain Cogn.53:82-94.

Mahady, G. B., Fong, H. H. S. and Farnsworth, N. R. (2001): Botanical dietary supplements: quality, safety and efficacy. Lisse, The Netherlands : Swets and Zeilinger. 
Marczinski, C. A. and Fillmore, M. T. (2006): Clubgoers and their trendy cocktails: implications of mixing caffeine into alcohol on information processing and subjective reports on intoxication. Exp Clin Psychopharmacol. 14:450-8.

Markowicz-Bastos, D. H., Moura de Oliveira, D., TeixeiraMatsumoto, R. L., De Oliveira-Carvalho, P. and Ribeiro, M. L. (2007): Yerba mate: pharmacological properties, research and biotechnology. Med Aromat Plant Sci Biotech. 1:37-46.

Mattei, R., Dias, R. F., Espinola, E. B., Carlini, E. A. and Barros, S. B. M. (1998): Guarana (Paullinia cupana): toxic behavioral effects in laboratory animals and antioxidant activity in vitro. $J$ Enthnopharmacol. 60:111-6.

Miller, K. E. (2008): Energy drinks, race, and problem behavior among college students. J Adolesc Health. 43:490-7.

Mintel Global New Products Database (2009): Energy drink ingredients continue down unhealthy path. Available from: < http://www.mintel.com/pressrelease/Energy-drink-ingredients-continuedown-unhealthy-path?id=386 >.

Munro, I. C. and Renwick, A. G. (2006): The 5th workshop on the assessment of adequate intake of dietary amino acids: general discussion 2. $J$ Nutr. 136:1755S-7S.

Nam, M. H., Kim, S. I., Liu, J. R., Yang, D. C., Lim, P. Y., Kwon, K. H., Yoo, J. S. and Park, Y. M. (2005): Proteomic analysis of Korean ginseng (Panax ginseng C.A. Meyer). J Chromatogr. B 815:14755.

Nawrot, P., Jordan, S., Eastwood, J., Rotstein, J., Hugenholtz, A. and Feely, M. (2003): Effects of caffeine on human health. Food Addit Contam 20:1-30.

Nworah, N. (2007): A Super-Charged Nation. http://thelongharmattanseason.blogspot.com/

O'Brien, M. C., McCoy, T. P, Rhodes, S. D., Waginer, B. S. and Wolfson, M. (2008): Caffeinated cocktails: energy drink consumption, high-risk drinking, and alcohol-related consequences among college students. Acad Emerg Med. 15:453-60.

Oteri, A., Salvo, F., Caputi, A. P. and Calapai, G. (2007): Intake of energy drinks in association with alcoholic beverages in a cohort of students of the School of Medicine of the University of Messina. Alcohol Clin Exp Res. 31:1677-80.

Pettenuzzo, L. F., Noschang, C., Von Pozzer Toigo, E., Fachin, A., Vendite, D. and Dalmaz, C. (2008): Effects of chronic administration of caffeine and stress on feeding behavior of rats. Physiol Behav. 95:295-301.

Ragsdale, F. R., Gronli, T. D., Batool, N., Haight, N., Mehaffey, McMahon, E. C., Nalli, T. W., Mannello, C. M., Sell, C. J., McCann, P. J., Kastello, G. M., Hooks, T. and Wilson, T. (2009): Effect of Red Bull energy drink on cardiovascular and renal function. Amino Acids. DOI:10.1007/s00726-009-0330-z.

Reissig, C. J., Strain, E. C. and Griffiths, R. R. (2009): Caffeinated energy drinks a growing problem. Drug Alcohol Depend. 99:1-10.
Safranow, K. and Machoy, Z. (2005): Methylated purines in urinary stones. Clinical Chem. 51:1493-8.

Scholey, A. B. and Kennedy, D. O. (2004): Cognitive and physiological effects of an "energy drink": an evaluation of the whole drink and of glucose, caffeine and herbal flavoring fractions. Psychopharmacology. 176:320-30.

Scholey, A. and Haskell, C. (2008): Neurocognitive effects of guarana plant extract. Drugs Future. 33:86974.

Seidl, R., Peyrl, A., Nicham, R. and Hauser, E. (2000): A taurine- and caffeine-containing drink stimulates cognitive performance and well-being. Amino Acids. 19:635-42.

Shao, A. and Hathcock, J. N. (2008): Risk assessment for the amino acids taurine, L-glutamine and Larginine. Regul Toxicol Pharmacol. 50:376-99.

Smit, H. J. and Rogers, P. J. (2002): Effects of energy drinks on mood and mental performance: critical methodology. Food Qual Pref. 13:31726.

Smit, H. J., Cotton, J. R., Hughes, S. C. and Rogers, P. J. (2004): Mood and cognitive performance effects of "energy" drink constituents: caffeine, glucose and carbonation. Nutr Neurosci. 7:127-39.

Steinke, L., Lanfear, D. E., Dhanapal, V. and Kalus, J. S. 2009): Effect of "energy drink" consumption on hemodynamic and electrocardiographic parameters in healthy young adults. Ann Pharmacother. 43:596-602.

Stipanuk, M. H. (2004): Role of liver in the regulation of body cysteine and taurine levels: a brief review. Neurochem Res. 29:105-10.

Taisho Pharmaceutical Co., Ltd. (2009): Available from: $<$

http://www.taisho.co.jp/en/company/profile/hist ory/index.html $>$.

Triebel, S., Sproll, C., Reusch, H., Godelmann, R. and Lachenmeier, D. W. (2007): Rapid analysis of taurine in energy drinks using amino acid analyzer and Fourier transform infrared (FTIR) spectroscopy as basis for toxicological evaluation. Amino Acids. 33:451-7.

Umana-Alvarado, M. and Moncada-Jimenez, J. (2004): The effect of an energy drink on aerobic performance in male athletes. Med Sci Sports Exer. 36:S174-5.

Warburton, D. M., Bersellini, E. and Sweeney, E. (2001): An evaluation of a caffeinated taurine drink on mood, memory and information processing in healthy volunteers without caffeine abstinence. Psychopharmacology (Berlin). 158:322-8.

Wardlaw, G. M. and Smith, A. M. (2009): Contemporary nutrition a functional approach. New York : McGraw-Hill.

Weckerle, C. S., Stutz, M. A. and Baumann, T. W. (2003): Purine alkaloids in Paullinia. Phytochem. 64:735-42.

Zhang, M., Bi, L. F., Fang, J. H., Su, X. L., Da, G. L., Kuwamori, T. and Kagamimori, S. (2004): Beneficial effects of taurine on serum lipids in overweight or obese non-diabetic subjects. Amino Acids. 26:267-71. 